\title{
Association of prenatal antibiotics with measures of infant adiposity and the gut microbiome
}

\author{
Mingyu Zhang ${ }^{1 \dagger}\left(\mathbb{D}\right.$, Moira K. Differding ${ }^{1 \dagger}$, Sara E. Benjamin-Neelon ${ }^{2}$, Truls $\varnothing$ stbye $^{3}$, Cathrine Hoyo ${ }^{4}$
} and Noel T. Mueller ${ }^{1,5^{*}}$ (1)

\begin{abstract}
Background: Prenatal antibiotic exposure has been associated with an altered infant gut microbiome composition and higher risk of childhood obesity, but no studies have examined if prenatal antibiotics simultaneously alter the gut microbiome and adiposity in infants.

Method: In this prospective study (Nurture: recruitment 2013-2015 in North Carolina, United States), we examined in 454 infants the association of prenatal antibiotic exposure (by any prenatal antibiotic exposure; by trimester of pregnancy; by number of courses; by type of antibiotics) with infant age- and sex-specific weight-for-length z score (WFL-z) and skinfold thicknesses (subscapular, triceps, abdominal) at 12 months of age. In a subsample, we also examined whether prenatal antibiotic exposure was associated with alterations in the infant gut microbiome at ages 3 and 12 months.

Results: Compared to infants not exposed to prenatal antibiotics, infants who were exposed to any prenatal antibiotics had 0.21 (95\% confidence interval [Cl] 0.02, 0.41) higher WFL-z at 12 months, and 0.28 (95\% Cl 0.02, 0.55) higher WFL-z if they were exposed to antibiotics in the second trimester, after adjustment for potential confounders, birth weight, and gestational age. We also observed a dose-dependent association (P-value for trend $=0.006$ ) with infants exposed to $\geq 3$ courses having $0.41(95 \% \mathrm{Cl} 0.13,0.68)$ higher WFL-z at 12 months. After further adjustment for delivery method, only second-trimester antibiotic exposure remained associated with higher infant WFL-z $(0.27,95 \% \mathrm{Cl}$ $0.003,0.54)$ and subscapular skinfold thickness $(0.49 \mathrm{~mm}, 95 \% \mathrm{Cl} 0.11,0.88)$ at 12 months. Infants exposed to secondtrimester antibiotics versus not had differential abundance of 13 bacterial amplicon sequence variants (ASVs) at age 3 months and 17 ASVs at 12 months (false discovery rate adjusted P-value <0.05).
\end{abstract}

Conclusions: Prenatal antibiotic exposure in the second trimester was associated with an altered infant gut microbiome composition at 3 and 12 months and with higher infant WFL-z and subscapular skinfold thickness at 12 months.

Keywords: Gut microbiome, Pediatric obesity, Antibiotic, Child health, Prenatal exposure, Pregnancy

\section{Background}

Despite efforts to prevent obesity, the prevalence of childhood obesity has more than tripled in the past 40 years [1]. It reached a historical high of $18.5 \%$ in $2015-2016$ in

*Correspondence: nmuelle4@jhu.edu

${ }^{\dagger}$ Mingyu Zhang and Moira K. Differding contributed equally to this work

${ }^{1}$ Department of Epidemiology, Johns Hopkins Bloomberg School

of Public Health, Baltimore, MD, USA

Full list of author information is available at the end of the article the United States (US) [2]. Given that one in seven children ages $2-5$ years are obese [2], identifying ways to prevent obesity from earlier life stages is needed. One compelling target for the prevention of early life obesity is the infant gut microbiome [3]. Prenatal antibiotic exposure has been shown to disturb the colonization and maturation of the infant microbiome [3, 4]. Recently, there has been growing interest in understanding whether prenatal antibiotics alter child growth and adiposity. While findings have been inconsistent regarding 
the association of any antibiotic exposure in pregnancy with child obesity, many showed a positive association of second-trimester antibiotic exposure with child weight [5-8]. However, no studies have examined whether prenatal antibiotics simultaneously affect adiposity and the gut microbiome in infancy. To address this gap, we examined associations of prenatal antibiotics with infant weight and adiposity measures at 12 months and, for mechanistic insight, explored associations with the infant gut microbiome at ages 3 and 12 months.

\section{Methods}

Nurture is a prospective birth cohort that recruited mothers from 2013 to 2015 in Durham, North Carolina, US. A detailed description of the cohort and data collection process is provided elsewhere $[9,10]$. We included singleton infants born after 28 weeks gestation with no congenital abnormalities. We obtained written informed consent from each mother at recruitment and again shortly after delivery. In this analytic dataset, we included 454 of the 666 mother-infant dyads that had at least one measurement of infant weight-for-length $z$ score (WFL-z) or skinfold thickness at 12 months.

We determined maternal and infant oral antibiotic intake from questionnaires and confirmed for those with medical records data. We categorized antibiotics based on the Anatomical Therapeutic Chemical classification system [11]: tetracyclines (J01A); beta-lactam antibacterials, penicillins (J01C); other beta-lactam antibacterials (J01D); sulfonamides and trimethoprim (J01E); macrolides, lincosamides, streptogramins (J01F); quinolone antibacterial (J01M); aminoglycoside antibacterials (J01G); and other antibacterials (J01X). Infant weight, length, and skinfold (subscapular, triceps, abdominal) thicknesses were measured by trained home visitors at 12 months. We calculated the age- and sex-specific WFL-z using the World Health Organization Child Growth Standards [12]. The sum of subscapular and triceps skinfold thicknesses (SS + TR) represents overall adiposity and the ratio of subscapular to triceps skinfold thicknesses (SS/TR) represents central adiposity.

Confounders were defined as variables both related to the exposure and the outcome but not in the causal pathway. Pre-selected potential confounders included maternal age at delivery (continuous variable), race (Black or African American; White; others), marital status (married or living with a partner; others), education $(\leq$ high school graduate; some college; $\geq$ college graduate), annual household income $(\leq \$ 20,000 ; \$ 20,001$ to $\$ 40,000 ; \geq \$ 40,001$ ), smoked during pregnancy (yes; no), and maternal pre-pregnancy body mass index (BMI, calculated as weight $(\mathrm{kg}) /[\text { height }(\mathrm{m})]^{2}$, continuous variable). Other covariates included delivery method (vaginal delivery; cesarean delivery), infant sex (male; female), birth weight (continuous variable), and gestational age (continuous variable). All covariates were extracted from or calculated based on questionnaires at recruitment and during home visits.

The primary outcome was infant WFL-z. Secondary outcomes included subscapular, triceps, and abdominal skinfold thicknesses, SS + TR, and SS/TR. We used multivariable linear regression models to estimate the difference in these outcomes at 12 months by any prenatal antibiotic exposure (yes; no), timing of exposure (trimester of pregnancy), number of courses, and types of antibiotics, adjusting for potential confounders (Model 1 ). We then added infant birth weight and gestational age (Model 2), and further added infant delivery method into the regression models (Model 3). We conducted sensitivity analyses by further adjusting for infant antibiotic intake in the first year of life in Model 1, and by examining if maternal antibiotic use in the first year after delivery associated with infant WFL-z at 12 months. We considered a two-sided $\mathrm{P}$-value $<0.05$ as statistically significant.

We also collected fresh stool at 3 months (in 68 infants) and 12 months (in 50 infants) and conducted 16S rRNA sequencing of the $\mathrm{V} 4$ region (see Additional file 1: Materials for full microbiome methods). We then examined the association of prenatal antibiotic exposure with differential microbial relative abundance, using beta-binomial regression models and Wald tests, accounting for sequencing depth and within-sample taxa correlation [13]. In these analyses, we used the false discovery rate (FDR) adjustment for multiple comparisons and twosided FDR-adjusted P-value $<0.05$ was defined as statistically significant. We conducted all analyses using Stata 15.1 (StataCorp, College Station, TX) and R 3.5.1 (R Foundation for Statistical Computing, Vienna, Austria).

\section{Results}

Of the 454 mothers included in the analysis, 217 (47.80\%) took $\geq 1$ course of antibiotics during pregnancy; 77 (16.96\%) took $\geq 3$ courses; and 60 (13.22\%), 69 (15.20\%), and 146 (32.16\%) took antibiotics during the first, second, and third trimester, respectively. Mothers who took antibiotics during pregnancy had higher pre-pregnancy BMI and were more likely to take antibiotics in the first year after delivery. Their infants were also more likely to have received antibiotics in the first year of life (Table 1).

Table 2 shows the association between prenatal antibiotic exposure and infant WFL-z at 12 months. After adjusting for potential confounders (Model 1), infants exposed to prenatal antibiotics had 0.23 (95\% CI 0.02, 0.43) higher WFL-z at 12 months, compared to infants who were not exposed. There was also a 
Table 1 Baseline maternal/household and infant characteristics by prenatal antibiotic exposure $(n=454)$

\begin{tabular}{|c|c|c|c|}
\hline \multirow[t]{2}{*}{ Variable, $n(\%)^{a}$} & \multicolumn{2}{|c|}{ Prenatal antibiotic exposure } & \multirow[t]{2}{*}{ P-value } \\
\hline & No & Yes & \\
\hline Number of participants & 237 & 217 & \\
\hline \multicolumn{4}{|l|}{ Maternal/household characteristics } \\
\hline Age at delivery, years, mean (SD) & $27.58(6.15)$ & $28.27(5.53)$ & 0.22 \\
\hline Pre-pregnancy BMI, kg/m², mean (SD) & $28.41(7.63)$ & $32.47(10.58)$ & $<0.001$ \\
\hline Race & & & 0.58 \\
\hline Black or African American & $157(66.5 \%)$ & $148(68.2 \%)$ & \\
\hline White & $50(21.2 \%)$ & $49(22.6 \%)$ & \\
\hline Others & $29(12.3 \%)$ & $20(9.2 \%)$ & \\
\hline Married or living with a partner & & & 0.70 \\
\hline Yes & $139(58.6 \%)$ & $132(60.8 \%)$ & \\
\hline No & $98(41.4 \%)$ & $85(39.2 \%)$ & \\
\hline Education & & & 0.30 \\
\hline$\leq$ High school graduate & $102(43.0 \%)$ & $103(47.5 \%)$ & \\
\hline Some college & $93(39.2 \%)$ & $70(32.3 \%)$ & \\
\hline$\geq$ College graduate & $42(17.7 \%)$ & $44(20.3 \%)$ & \\
\hline Annual household income & & & 0.95 \\
\hline$\leq \$ 20,000$ & $138(59.7 \%)$ & $129(60.8 \%)$ & \\
\hline$\$ 20,001$ to $\$ 40,000$ & $44(19.0 \%)$ & $41(19.3 \%)$ & \\
\hline$\geq \$ 40,001$ & $49(21.2 \%)$ & $42(19.8 \%)$ & \\
\hline Smoked during pregnancy & & & 1.00 \\
\hline Yes & $36(15.6 \%)$ & $33(15.6 \%)$ & \\
\hline No & $195(84.4 \%)$ & $178(84.4 \%)$ & \\
\hline Type of breastfeeding & & & 0.13 \\
\hline Exclusive breastfeeding & $18(7.8 \%)$ & $10(4.8 \%)$ & \\
\hline Exclusive formula & $46(20.0 \%)$ & $56(26.9 \%)$ & \\
\hline Mixed feeding method & $166(72.2 \%)$ & $142(68.3 \%)$ & \\
\hline Maternal antibiotic use in the first year after delivery & & & 0.001 \\
\hline Yes & $67(28.3 \%)$ & $93(42.9 \%)$ & \\
\hline No & $170(71.7 \%)$ & $124(57.1 \%)$ & \\
\hline \multicolumn{4}{|l|}{ Infant characteristics } \\
\hline Sex & & & 0.64 \\
\hline Female & $117(49.4 \%)$ & $112(51.6 \%)$ & \\
\hline Male & $120(50.6 \%)$ & $105(48.4 \%)$ & \\
\hline Gestational age, week, mean (SD) & $38.74(1.38)$ & $38.46(1.72)$ & 0.05 \\
\hline Birth weight, kilogram, mean (SD) & $3.20(0.50)$ & $3.23(0.53)$ & 0.59 \\
\hline Infant antibiotic use in the first year of life & & & 0.01 \\
\hline Yes & $84(35.4 \%)$ & $102(47.0 \%)$ & \\
\hline No & $153(64.6 \%)$ & $115(53.0 \%)$ & \\
\hline
\end{tabular}

$S D$ standard deviation, $B M I$ body mass index

a Unless otherwise indicated

dose-dependent association by courses of prenatal antibiotics (P-value for trend $=0.006$ ): compared to infants not exposed, infants who were exposed to 1,2 , or $\geq 3$ courses of prenatal antibiotics had 0.09 (95\% CI -0.19 , 0.37), 0.19 (95\% CI $-0.10,0.48$ ), or 0.40 (95\% CI 0.11 , $0.68)$ higher WFL-z at 12 months, respectively. While there were no significant associations of any prenatal antibiotic exposure with infant skinfold thicknesses, SS + TR, or SS/TR at 12 months after adjusting for confounders (Additional file 2: Table S1), we found that $\geq 3$ courses of prenatal antibiotics was associated with 0.68 
Table 2 Association (with $95 \%$ confidence interval) of prenatal antibiotics and infant weight-for-length $z$ score at 12 months

\begin{tabular}{|c|c|c|c|c|c|}
\hline & $\mathrm{N}$ & $\begin{array}{l}\text { Model 1: adjusted } \\
\text { for potential } \\
\text { confounders }^{\mathrm{a}}\end{array}$ & $\begin{array}{l}\text { Model 2: model } 1+\text { infant } \\
\text { birth weight }+ \text { infant } \\
\text { gestational age }\end{array}$ & $\begin{array}{l}\text { Model 3: model } \\
2+\text { delivery } \\
\text { method }\end{array}$ & $\begin{array}{l}\text { Sensitivity analysis: model } \\
1+\text { infant antibiotic intake } \\
\text { in the first year }\end{array}$ \\
\hline $\mathrm{N}$ & & 410 & 408 & 405 & 410 \\
\hline \multicolumn{6}{|l|}{ Any prenatal antibiotic exposure } \\
\hline No & 237 & Reference group & & & \\
\hline Yes & 217 & $0.23(0.02,0.43)$ & $0.21(0.02,0.41)$ & $0.14(-0.09,0.37)$ & $0.22(0.02,0.43)$ \\
\hline \multicolumn{6}{|c|}{ Number of courses during the prenatal period } \\
\hline 0 & 237 & Reference group & & & \\
\hline 1 & 73 & $0.09(-0.19,0.37)$ & $0.10(-0.17,0.38)$ & $0.07(-0.21,0.35)$ & $0.09(-0.20,0.37)$ \\
\hline 2 & 67 & $0.19(-0.10,0.48)$ & $0.13(-0.15,0.42)$ & $0.05(-0.28,0.37)$ & $0.19(-0.10,0.48)$ \\
\hline$\geq 3$ & 77 & $0.40(0.11,0.68)$ & $0.41(0.13,0.68)$ & $0.33(0.02,0.63)$ & $0.39(0.11,0.68)$ \\
\hline \multicolumn{6}{|c|}{ Timing of prenatal antibiotic exposure } \\
\hline \multicolumn{6}{|c|}{ Reference group: infants not exposed to antibiotics in each specific time period } \\
\hline First trimester & 60 & $0.21(-0.09,0.51)$ & $0.16(-0.13,0.45)$ & $0.15(-0.14,0.44)$ & $0.21(-0.09,0.50)$ \\
\hline Second trimester & 69 & $0.28(0.002,0.55)$ & $0.28(0.02,0.55)$ & $0.27(0.003,0.54)$ & $0.27(-0.001,0.55)$ \\
\hline Third trimester & 146 & $0.17(-0.05,0.38)$ & $0.15(-0.06,0.37)$ & $0.04(-0.21,0.29)$ & $0.16(-0.05,0.38)$ \\
\hline $\begin{array}{l}\text { First year after delivery } \\
\text { (maternal intake) }\end{array}$ & 160 & $0.05(-0.17,0.26)$ & $-0.02(-0.23,0.18)$ & $-0.05(-0.26,0.16)$ & $0.05(-0.17,0.26)$ \\
\hline \multicolumn{6}{|l|}{ Type $^{b}$ of antibiotic exposure } \\
\hline \multicolumn{6}{|c|}{ Reference group: infants not exposed to each specific type of antibiotic } \\
\hline $\begin{array}{l}\text { Beta-lactam antibacterials, } \\
\text { penicillins }\end{array}$ & 30 & $0.10(-0.30,0.49)$ & $0.08(-0.31,0.46)$ & $0.08(-0.31,0.46)$ & $0.10(-0.30,0.49)$ \\
\hline $\begin{array}{l}\text { Other beta-lactam antibac- } \\
\text { terials }\end{array}$ & 146 & $0.19(-0.02,0.41)$ & $0.16(-0.05,0.37)$ & $0.03(-0.24,0.29)$ & $0.19(-0.02,0.41)$ \\
\hline $\begin{array}{l}\text { Sulfonamides and trimetho- } \\
\text { prim }\end{array}$ & 15 & $-0.05(-0.58,0.48)$ & $-0.02(-0.53,0.49)$ & $-0.04(-0.55,0.47)$ & $-0.06(-0.59,0.47)$ \\
\hline $\begin{array}{l}\text { Macrolides, lincosamides, } \\
\text { streptogramins }\end{array}$ & 46 & $0.23(-0.11,0.56)$ & $0.23(-0.10,0.56)$ & $0.21(-0.12,0.53)$ & $0.23(-0.11,0.56)$ \\
\hline $\begin{array}{l}\text { Aminoglycoside antibac- } \\
\text { terials }\end{array}$ & 23 & $0.34(-0.10,0.78)$ & $0.32(-0.11,0.75)$ & $0.24(-0.19,0.68)$ & $0.33(-0.11,0.78)$ \\
\hline Other antibacterials & 69 & $0.35(0.08,0.63)$ & $0.34(0.08,0.61)$ & $0.32(0.05,0.59)$ & $0.35(0.08,0.63)$ \\
\hline
\end{tabular}

a Potential confounders included maternal age at delivery, race, marital status, educational, annual household income, smoke during pregnancy, and pre-pregnancy body mass index

b Tetracyclines $(J 01 \mathrm{~A})$ and quinolone antibacterial $(\mathrm{J} 01 \mathrm{M})$ were excluded due to the small number of people who took them $(\mathrm{n}<10)$

(95\% CI $0.12,1.24) \mathrm{mm}$ increase in infant abdominal skinfold thickness at 12 months.

Associations remained when we further adjusted for infant birth weight and gestational age at birth (Model 2) or infant antibiotic intake in the first year of life (sensitivity analysis). When we further added delivery method to Model 2, only second-trimester antibiotic intake remained associated with infant WFL-z at 12 months $(0.27,95 \%$ CI $0.003,0.54)$ (Model 3). The second trimester was also the only period in which antibiotic exposure was associated with higher 12-month subscapular skinfold thickness [0.50 (95\% CI 0.12, 0.89) $\mathrm{mm}$ increase].

Given the persistent association of second-trimester antibiotic exposure with infant 12-month WFL-z, we next examined in a subsample of infants whether second-trimester antibiotic exposure was associated with the infant gut microbiome. Infants exposed to antibiotics in the second trimester versus not exposed had significantly different relative abundance of 13 bacterial amplicon sequence variants (ASVs) at age 3 months and 17 ASVs at 12 months (Fig. 1). Detailed information of these ASVs can be found in Additional file 3: Table S2.

\section{Discussion}

In our low-income, multi-racial prospective birth cohort from North Carolina, we found a dose-dependent association between number of prenatal antibiotic courses and higher infant WFL-z at 12 months, after controlling for potential confounders. After further controlling for delivery mode, only second-trimester antibiotic exposure 


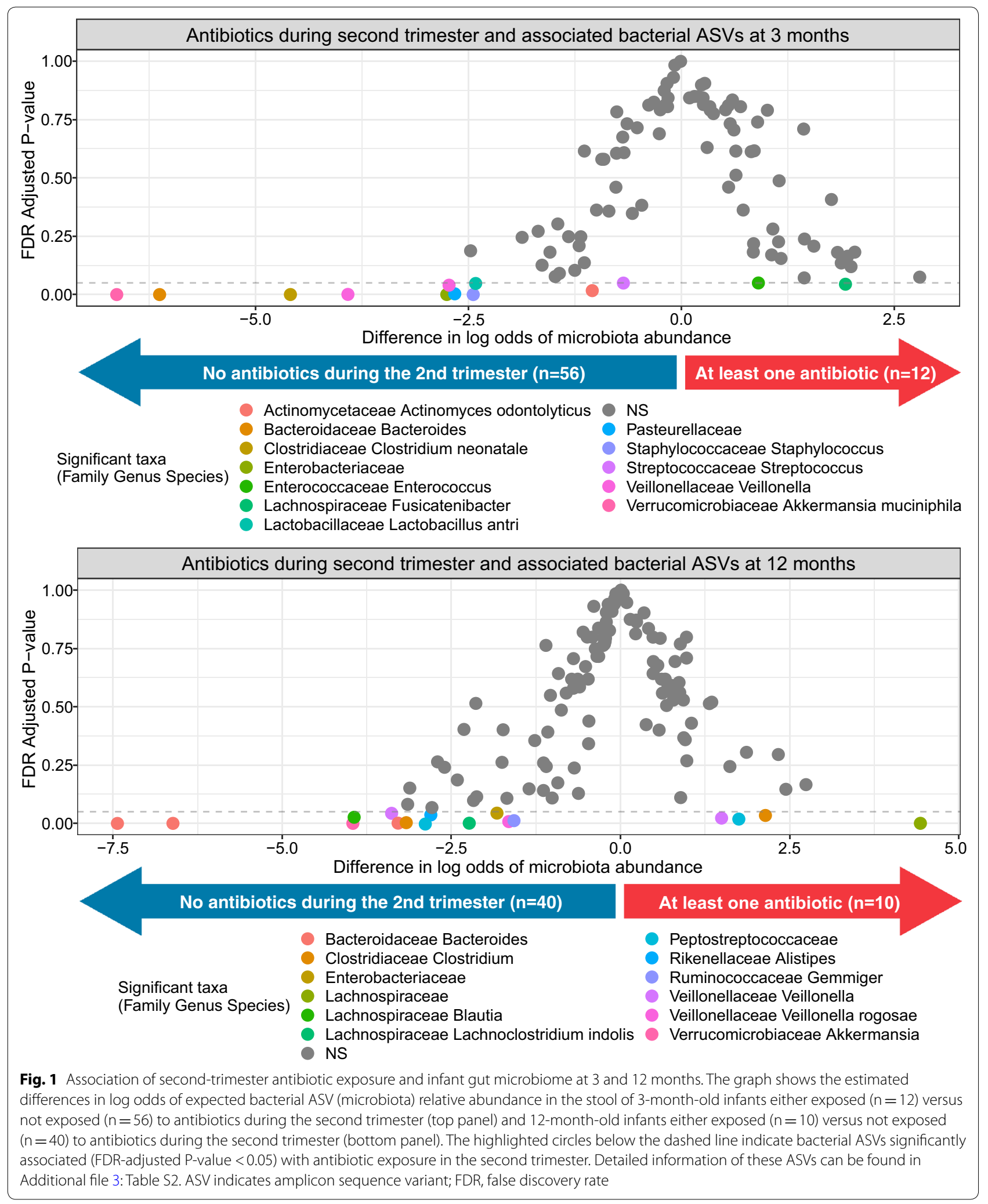


remained associated with infant weight and adiposity measures at 12 months. Analysis of the infant gut microbiome showed that prenatal antibiotic exposure in the second trimester was associated with differential abundance of 13 unique bacterial ASVs at age 3 months and 17 ASVs at 12 months.

Our group previously reported an association between antibiotic exposure in pregnancy and higher risk of child obesity at 7 years [5]. Several studies have found similar associations in children ages 2 years [7] and 7-16 years [6], while others did not find an association in children ages 3 years [14], 5 years [15], or 4 or 7 years [8]. Consistent with our current study, many have found stronger associations for repeated exposure [6-8] and for exposure in the second trimester [5-8]. In our current study, we showed that second-trimester antibiotic exposure was associated not only with infant weight but also with greater subscapular skinfold thickness at 12 months of age.

The second trimester of pregnancy, when the fetus and fetal gut are rapidly developing [16], may be a particularly susceptible window for immunometabolic programming by the maternal microbiome. We showed that antibiotic exposure in the second trimester is associated with differential abundance of 13 and 17 ASVs in the infant gut microbiome at 3 and 12 months, respectively. The abundance of some taxa remained different over time, including higher abundance of bacteria in the Lachnospiraceae family, which has been associated with greater child weight [17], and lower abundance of Akkermansia muciniphila, a bacterium associated with metabolic health [18]. An experimental murine model [19] and an observational study in infants delivered preterm [20] also found that prenatal antibiotic exposure is associated with an altered infant microbiome composition. Other studies have found trimester-specific associations of antibiotics with fetal adipokines and birth weight [21], and observed that antibiotic exposure in the second trimester is associated with higher risk of childhood obesity [5-8]. It is possible that antibiotic-induced changes to the maternal microbiota and their metabolites [22] may underlie these trimester-specific associations, but future studies, with stool and blood samples from both mothers and infants, are still needed to test this hypothesis.

There are several strengths of our study, including the confirmation of antibiotic records from the medical records, which reduced recall bias. These records also provided detailed information on the time prescribed, number of courses, and antibiotic type. Moreover, unlike previous studies, we used maternal antibiotic intake in the first year after delivery for comparison to see if the association is specific to pregnancy. In these analyses, maternal antibiotic intake in the first year after delivery was not associated with infant WFL-z at 12 months, implying that the association of prenatal antibiotics with infant weight is not due to maternal propensity for infection.

Some limitations also exist. Although we controlled for important confounders, we cannot rule out the possibility of residual confounding or confounding by indication for the antibiotic prescription (e.g., underlying infection). Moreover, we were not able to confirm maternal compliance with these prescriptions, thus misclassification of the prenatal antibiotic exposures might exist. However, such misclassification would most likely to be nondifferential by outcome and, if any, bias the association towards the null. Furthermore, we only collected stool from a subsample of infants, and we did not collect stool or vaginal samples from the mother to test whether antibiotic-induced changes to the microbiome mediated the observed associations with measures of adiposity.

\section{Conclusions}

Our findings suggest that prenatal antibiotic exposure in the second trimester is associated with an altered infant gut microbiome composition at 3 and 12 months and higher infant WFL-z and subscapular skinfold thickness at 12 months. Larger birth cohorts with repeated microbiome measures are needed to confirm our findings.

\section{Additional file}

\section{Additional file 1. Materials for full microbiome methods.}

Additional file 2: Table S1. Adjusted association (with 95\% confidence interval) of prenatal antibiotics and infant skinfold thicknesses at 12 months.

Additional file 3: Table S2. Associations of second trimester antibiotics and bacterial ASV (microbiota) abundance as shown in Fig. 1.

\section{Abbreviations}

US: United States; WFL-z: weight-for-length z score; FDR: false discovery rate; BMI: body mass index; SS: subscapular skinfold thickness; TR: triceps skinfold thickness; ASV: amplicon sequence variant.

\section{Acknowledgements}

Not applicable.

\section{Authors' contributions}

$\mathrm{MZ}$ and MKD analyzed the data and drafted the manuscript. SEBN, TO, $\mathrm{CH}$, and NTM contributed to writing the manuscript. All authors edited the final manuscript. All authors read and approved the final manuscript.

\section{Funding}

This study was supported by grants from the National Institutes of Health (R01DK094841), the Mid-Atlantic Nutrition Obesity Research Center (P30DK072488), and the Foundation for Gender Specific Medicine. Dr. Mueller is supported by the National Heart, Lung, and Blood Institute of the National Institutes of Health (K01HL 141589). The funders had no role in the design of the study, data collection and analysis, decision to publish, or preparation of the manuscript. The content is solely the responsibility of the authors and 
does not necessarily represent the official views of the National Institutes of Health.

\section{Availability of data and materials}

The datasets used in this study are potentially available from Dr. BenjaminNeelon with appropriate ethical and legal agreements in place.

\section{Ethics approval and consent to participate}

The study was approved by Duke University Medical Center IRB (human subjects committee) (Pro 00036242).

\section{Consent for publication}

Not applicable.

\section{Competing interests}

The authors declare that they have no competing interests.

\section{Author details}

1 Department of Epidemiology, Johns Hopkins Bloomberg School of Public Health, Baltimore, MD, USA. ${ }^{2}$ Department of Health, Behavior and Society, Johns Hopkins Bloomberg School of Public Health, Baltimore, MD, USA. ${ }^{3}$ Department of Community and Family Medicine, Duke University Medical Center, Durham, NC, USA. ${ }^{4}$ Department of Biological Sciences and Center for Human Health and the Environment, North Carolina State University, Raleigh, NC, USA. ${ }^{5}$ Welch Center for Prevention, Epidemiology and Clinical Research, Johns Hopkins University, Baltimore, MD, USA.

Received: 3 December 2018 Accepted: 6 June 2019

Published online: 21 June 2019

\section{References}

1. Fryar CD, Carroll MD, Ogden CL. Prevalence of Overweight and obesity among children and adolescents: United States, 1963-1965 Through 2011-2012. Health E-Stats; 2014. https://www.cdc.gov/nchs/data/hestat/ obesity_child_11_12/obesity_child_11_12.htm. Accessed 23 Apr 2019.

2. Hales CM, Fryar CD, Carroll MD, Freedman DS, Ogden CL. Trends in obesity and severe obesity prevalence in US youth and adults by sex and age, 2007-2008 to 2015-2016. JAMA. 2018;319(16):1723-5.

3. Mueller NT, Bakacs E, Combellick J, Grigoryan Z, Dominguez-Bello MG The infant microbiome development: mom matters. Trends Mol Med. 2015;21(2):109-17.

4. Zhang M, Litonjua AA, Mueller NT. Maternal antibiotic use and child asthma: is the association causal? Eur Respir J. 2018;52(1):1801007.

5. Mueller NT, Whyatt R, Hoepner $L$, et al. Prenatal exposure to antibiotics, cesarean section and risk of childhood obesity. Int J Obes. 2015:39(4):665-70.

6. Mor A, Antonsen S, Kahlert J, et al. Prenatal exposure to systemic antibacterials and overweight and obesity in Danish schoolchildren: a prevalence study. Int J Obes. 2015;39(10):1450-5.
7. Cassidy-Bushrow AE, Burmeister C, Havstad S, et al. Prenatal antimicrobial use and early-childhood body mass index. Int J Obes. 2018:42(1):1-7.

8. Wang B, Liu J, Zhang Y, et al. Prenatal exposure to antibiotics and risk of childhood obesity in a multicenter cohort study. Am J Epidemiol. 2018;187(10):2159-67.

9. Benjamin Neelon SE, Ostbye T, Bennett GG, et al. Cohort profile for the Nurture Observational Study examining associations of multiple caregivers on infant growth in the Southeastern USA. BMJ Open. 2017;7(2):e013939.

10. Mueller NT, Zhang M, Hoyo C, Østbye T, Benjamin-Neelon SE. Does cesarean delivery impact infant weight gain and adiposity over the first year of life? Int J Obes (Lond). 2018. https://doi.org/10.1038/s41366-018-0239-2.

11. ATC/DDD Index 2019; 2019. https://www.whocc.no/atc_ddd_index/. Accessed 23 Apr 2019.

12. WHO Child Growth Standards based on length/height. weight and age. Acta Paediatr Suppl. 2006:450:76-85.

13. Martin BD, Witten D, Willis AD. Modeling microbial abundances and dysbiosis with beta-binomial regression. arXiv e-prints; 2019. https://ui.adsab s.harvard.edu/abs/2019arXiv190202776M. Accessed 24 Apr 2019.

14. Poulsen MN, Pollak J, Bailey-Davis L, Hirsch AG, Glass TA, Schwartz BS. Associations of prenatal and childhood antibiotic use with child body mass index at age 3 years. Obesity (Silver Spring, Md). 2017;25(2):438-44.

15. Heerman WJ, Daley MF, Boone-Heinonen J, et al. Maternal antibiotic use during pregnancy and childhood obesity at age 5 years. Int J Obes. 2019. https://doi.org/10.1038/s41366-018-0316-6.

16. Malas MA, Aslankoc R, Ungor B, Sulak O, Candir O. The development of large intestine during the fetal period. Early Human Dev. 2004;78(1):1-13.

17. Tun MH, Tun HM, Mahoney JJ, et al. Postnatal exposure to household disinfectants, infant gut microbiota and subsequent risk of overweight in children. CMAJ. 2018;190(37):E1097-107.

18. Cani PD, de Vos WM. Next-generation beneficial microbes: the case of Akkermansia muciniphila. Front Microbiol. 2017;8:1765.

19. Yoshimoto A, Uebanso T, Nakahashi M, Shimohata T, Mawatari K, Takahashi A. Effect of prenatal administration of low dose antibiotics on gut microbiota and body fat composition of newborn mice. J Clin Biochem Nutr. 2018;62(2):155-60.

20. Zou ZH, Liu D, Li HD, et al. Prenatal and postnatal antibiotic exposure influences the gut microbiota of preterm infants in neonatal intensive care units. Ann Clin Microbiol Antimicrob. 2018;17(1):9.

21. Mueller NT, Rifas-Shiman SL, Blaser MJ, Gillman MW, Hivert MF. Association of prenatal antibiotics with foetal size and cord blood leptin and adiponectin. Pediatr Obes. 2017;12(2):129-36.

22. Farook VS, Reddivari L, Chittoor G, et al. Metabolites as novel biomarkers for childhood obesity-related traits in Mexican-American children. Pediatr Obes. 2015;10(4):320-7.

\section{Publisher's Note}

Springer Nature remains neutral with regard to jurisdictional claims in published maps and institutional affiliations.
Ready to submit your research? Choose BMC and benefit from:

- fast, convenient online submission

- thorough peer review by experienced researchers in your field

- rapid publication on acceptance

- support for research data, including large and complex data types

- gold Open Access which fosters wider collaboration and increased citations

- maximum visibility for your research: over $100 \mathrm{M}$ website views per year

At BMC, research is always in progress.

Learn more biomedcentral.com/submissions 